\title{
Potencial energético utilizando a produção de biogás em tratamento de esgoto
}

O avanço do processo de industrialização e urbanização trouxeram consequências, resultando em um crescimento da quantidade de efluentes com elevado teo de orgânicos, que podem se tornar o motivo de grandes impactos ambientais danosos e poluição dos corpos hídricos. Neste seguimento, estimular o saneamento ambiental e explorar o potencial de produção do biogás e seu uso na geração de energia das estações de tratamento de esgoto, baseado na tecnologia de saneamento já utilizado, pode ser uma alternativa viável. O gás metano, oriundo da degradação da matéria orgânica, poderia ser conduzido e queimado em motores geradores de energia, com o objetivo de minimizar os impactos ambientais e utilização do biogás, que é uma fonte de energia limpa e renovável. Desse modo, o presente trabalho pretende analisar o potencial do biogás para fins de aproveitamento energético, reduzir o impacto ambiental causado pela emissão do metano $(\mathrm{CH} 4)$ buscando uma perspectiva teórica na geração de eletricidade, possibilitando benefícios socioambientais. O estudo obteve os seguintes valores para o potencial de geração do biogás no âmbito Nacional do esgoto coletado e tratado, e do esgoto coletado e não tratado: 466,70Mm3/dia; e 163,17Mm3/dia, respectivamente. Já o potencial técnico de geração de eletricidade no âmbito Nacional para o esgoto coletado e tratado, e o esgoto coletado e não tratado foram de 7,583GWh.dia-1 e 2,651GWh.dia-1, respectivamente.

Palavras-chave: Aproveitamento; Biogás; Saneamento; Ambiental.

\section{Energy potential using biogas production in sewage treatment}

The advancement of the industrialization and urbanization process brought consequences, resulting in an increase in the amount of effluents with high organic content, which can become the cause of large harmful environmental impacts and pollution of water bodies. In this regard, stimulating environmental sanitation and exploiting the potential of biogas production and its use in the generation of energy from sewage treatment plants, based on the sanitation technology already in use, may be a viable alternative. Methane gas from degradation of organic matter could be driven and flared in energy-generating engines to minimize environmental impacts and use of biogas, which is a clean and renewable energy source. Thus, the present work intends to analyze the potential of biogas for energy use purposes, reduce the environmental impact caused by methane emission $(\mathrm{CH} 4)$ seeking a theoretical perspective on electricity generation, enabling social and environmental benefits. The study obtained the following values for the biogas generation potential in the National scope of collected and treated sewage, and collected and untreated sewage: $466,70 \mathrm{Mm} 3 /$ day; and $163,17 \mathrm{Mm} 3 /$ day, respectively. The technical potential for electricity generation at the National level for collected and treated sewage, and collected and untreated sewage, were 7,583GWh.dia-1 and 2,651GWh.dia-1, respectively.

Keywords: Harnessing; Biogas; Sanitation; Environmental.

\section{Topic: Engenharia Sanitária}

Reviewed anonymously in the process of blind peer
Received: 17/01/2019

Approved: 17/03/2019
Hector da Silva Santiago

Instituto Tocantinense Presidente Antônio Carlos Porto, Brasil http://lattes.cnpq.br/3819331993797020

hectorsp20@hotmail.com

Eduardo Lage Gouveia Santiago

Instituto Tocantinense Presidente Antônio Carlos Porto, Brasil http://lattes.cnpq.br/6181125172616043

eduardolage@itpacporto.com.br

\section{Referencing this:}

SANTIAGO, H. S.; SANTIAGO, E. L. G.. Potencial energético utilizando a produção de biogás em tratamento de esgoto. Engineering Sciences, v.7, n.1, p.73-80, 2019. DOI: http://doi.org/10.6008/CBPC23183055.2019 .001 .0008

DOI: 10.6008/CBPC2318-3055.2019.001.0008 


\section{INTRODUÇÃO}

Com o avanço do processo de industrialização e o crescimento econômico, vistos durante muito tempo como condições para o avanço da qualidade de vida da raça humana, foram consideradas as principais causadoras pelas agressões no meio ambiente e alterações das concentrações de gases de efeito estufa (GEE). Nesta situação, como consequência do processo de agroindustrialização e aumento populacional, ocasionou um crescimento na quantidade de efluentes com elevados teores de orgânicos, capazes de gerar fortes impactos ambientais negativos.

Desta maneira, a atual tecnologia utilizada nos sistemas de tratamento de esgoto pode ser cada vez mais eficiente, visto que todas as camadas da população têm a necessidade de saneamento básico. Sendo assim, estimular o saneamento ambiental e explorar o potencial energético das estações de tratamento de esgoto, baseado na tecnologia de saneamento já utilizado, pode ser uma alternativa viável. Além disto, com a obtenção do gás metano $\left(\mathrm{CH}_{4}\right)$, oriundo da degradação da matéria orgânica, poderia ser conduzido e queimado em motores geradores de energia com o objetivo de minimizar os impactos ambientais e utilização do biogás que é uma fonte de energia (FARIA,2012).

\section{REVISÃO TEÓRICA}

\section{Produto principal gerado através da biodigestão anaeróbia: Biogás}

O biogás era considerado meramente como um subproduto, alcançado a partir da decomposição anaeróbia (sem a presença de oxigênio) de resíduos orgânicos. Contudo, com a crise ambiental e o acelerado desenvolvimento econômico nos últimos anos, assim como a elevação do preço dos combustíveis convencionais, vêm crescendo o número de pesquisas e investimentos na geração de energia, com a utilização de novas fontes alternativas e atrativas economicamente, que possibilitem que recursos naturais esgotáveis sejam conservados (SALOMON, 2007). Segundo Castanon (2002), a composição média do biogás, proveniente da biodigestão anaeróbia, está descrita de acordo com a tabela 1.

Tabela 1: Composição da mistura gasosa do biogás.

\begin{tabular}{|c|c|}
\hline Gases & Intervalo (\%) \\
\hline Metano $\left(\mathrm{CH}_{4}\right)$ & $40-75$ \\
\hline Dióxido de Carbono $\left(\mathrm{CO}_{2}\right)$ & $25-40$ \\
\hline Oxigênio $\left(\mathrm{O}_{2}\right)$ & $0,1-1$ \\
\hline Nitrogênio $\left(\mathrm{N}_{2}\right)$ & $0,5-2,5$ \\
\hline Hidrogênio $\left(\mathrm{H}_{2}\right)$ & $1-3$ \\
\hline Ácido Sulfídrico $\left(\mathrm{H}_{2} \mathrm{~S}\right)$ & $0,1-0,5$ \\
\hline Monóxido de Carbono $(\mathrm{CO})$ & $0-0,1$ \\
\hline Amônia $\left(\mathrm{NH}_{3}\right)$ & $0,1-0,5$ \\
\hline
\end{tabular}

Fonte: Castanon (2002).

Uma mistura de gases constitui o biogás, no qual o metano $\left(\mathrm{CH}_{4}\right)$ juntamente com o dióxido de carbono $\left(\mathrm{CO}_{2}\right)$ estão em proporções maiores. A taxa de metano está entre 40 a $75 \%$ dependendo da fonte geradora, e o dióxido de carbono está entre 25 a 40\% (FARIA, 2012). Segundo Salomon (2007), o biogás, além de ser renovável e ser um subproduto da degradação de um resíduo, possui as seguintes vantagens: para as prefeituras, há uma maior aceitação social das instalações de saneamento, visto que serão gerenciadas de 
forma mais adequada; alternativa de venda de eletricidade a rede, possibilitando receita extra; e colaboração para a viabilidade econômica no tratamento do lixo.

Para a sociedade: contribuição para a viabilidade econômica do saneamento básico; possibilidade de geração de emprego e redução de subempregos; e a partir de uma fonte renovável tratada como resíduo, possibilita a geração descentralizada e próxima aos pontos de carga. Para o meio ambiente: diminuição das emissões de metano para a atmosfera, uma vez que seu potencial de poluição global é 21 vezes maior que o CO2; diminuição do uso de combustíveis fósseis, que são os responsáveis principais pelo efeito estufa; e diminuição da geração de odor para as vizinhanças.

Como principais barreiras existentes, tem-se: tecnológicas, no que se refere à limpeza do gás; e necessidade de planta de demonstração no país. Na seara econômica, o investimento elevado dependendo da fonte de biogás; e a análise econômica convencional, desconsidera benefícios ambientais (emissões de metano - saneamento).

\section{Poder calorífico do biogás}

Gerado por meio da degradação da matéria orgânica, o biogás é um gás inflamável, fermentado dentro de limites de teor de umidade, temperatura e acidez, dentro de um ambiente impermeável ao ar e realizado por microrganismos (GENOVESE et al., 2006). O potencial teórico de energia compreendido em alguma fonte de combustível pode ser determinado através do poder calorifico inferior ( $\mathrm{PCl})$. No biogás, o principal componente é o metano, no qual possui uma composição média de $50 \%$ a $65 \%$ de $\mathrm{CH} 4$, e $25 \%$ a $45 \%$ de dióxido de carbono ( $\mathrm{CO} 2$ ), e pequenas parcelas de $\mathrm{H} 2 \mathrm{~S}, \mathrm{~N} 2, \mathrm{H} 2, \mathrm{CO}, \mathrm{O}$, com cerca de $5500 \mathrm{Kcal} / \mathrm{m}^{3}$ de poder calorífico, se sua proporção em metano for aproximadamente de 60\% (IANNICELLI, 2008). O PCI do biogás é demonstrado na tabela 2.

Tabela 2: Poder calorífico inferior de gases.

\begin{tabular}{|c|c|}
\hline Gás & $\mathbf{P C l}\left(\mathbf{K c a l} / \mathbf{m}^{3}\right)$ \\
\hline Metano & 8.500 \\
\hline Propano & 22.000 \\
\hline Butano & 28.000 \\
\hline Gás de Cidade & 4.000 \\
\hline Gás Natural & 8.554 \\
\hline Biogás & 5.500 \\
\hline
\end{tabular}

Fonte: Genovese et al. (2006).

O uso direto do biogás oriundo dos biodigestores, sem purificação, utilizado no acionamento de bombas hidráulicas e geradores de energia, pode ser vantajoso como aproveitamento energético. No entanto, na queima in natura do biogás, devido a presença do $\mathrm{CO} 2$, é mais lenta, e energeticamente, libera uma menor quantia de calor por unidade de massa que os gases combustíveis convencionais, bem como o gás natural e o gás liquefeito de petróleo, devendo ser considerado no dimensionamento dos equipamentos ou reajustados dos já existentes. O poder calorifico do gás natural é, em média, de $43.500 \mathrm{~kJ} / \mathrm{Kg}$, e o gás liquefeito de petróleo é de $46.000 \mathrm{~kJ} / \mathrm{kg}$, versus $19.500 \mathrm{KJ} / \mathrm{Kg}$ do biogás (SOUZA et al., 2010). 


\section{METODOLOGIA}

O presente trabalho objetiva avaliar o potencial de produção do biogás no âmbito Nacional no ano de 2016 para o aproveitamento na geração de energia elétrica como fonte alternativa. A determinação da produção do biogás e da produção de eletricidade será por meio de cálculos matemáticos estimados. 0 estudo foi desenvolvido por meio de pesquisas bibliográficas, e os dados obtidos para os cálculos foram através do SNIS (Sistema Nacional de informações sobre Saneamento), juntamente com pesquisas na literatura.

Os dados obtidos no SNIS foram os seguintes: o volume diário em metros cúbicos de esgoto coletado e tratado; e volume de esgoto coletado e não tratado. Ambos os dados no âmbito Nacional e pelas regiões do Brasil, dividindo-se o volume por 365 dias para a obtenção da vazão média diária calculada de acordo com a equação $Q=V / T$, na qual $Q=$ vazão média $\left(m^{3}\right.$.dia- 1$) ; V=$ Volume $\left(m^{3}\right.$.dia- 1$) ;$ e $T=$ tempo (365 dias). Para efeito de cálculos, alguns dados foram adotados de acordo com a literatura consultada, como a eficiência da remoção de DQO do reator UASB que foi adotado 70\% segundo Sousa (2004), e a DQO característica do esgoto doméstico, que de acordo com Gonçalves et al. (1997), assim como Burton et al. (2005), ambos os autores admitem a concentração média de $500 \mathrm{mg} / \mathrm{L}$ de DQO.

\section{Cálculo de estimativa de produção de biogás}

A produção do biogás pode ser realizada a partir da estimativa da carga de DQO afluente ao reator, convertida no gás metano, conforme apresentado matematicamente na equação proposta, na qual alguns valores foram pré-definidos para efeito de cálculo. De acordo com o cálculo do FINEP (2009), na estimativa da produção de biogás produzida na digestão anaeróbia, foi adotado valor de $0,25 \mathrm{~m}^{3} \mathrm{CH} 4 . \mathrm{kg}^{-1} \mathrm{DQO}$, que com uma eficiência do processo de biodigestão de $80 \%$, obteve-se $0,20 \mathrm{~m}^{3} \mathrm{CH} 4 \cdot \mathrm{kg}^{-1} \mathrm{DQO}$ de biomassa disponível.

Baseado na relação de produção de metano por DQO removida e na concentração de metano no biogás, determina-se a produção de metano em $\mathrm{m}^{3} / \mathrm{dia}$, podendo ser calculada pela equação $\mathrm{PM}=$ Vef.(DQOe).Y/ $\mathrm{C}_{\mathrm{CH} 4}$, onde: $\mathrm{PM}=$ produção de Metano; Vef é a vazão de biomassa através de biodigestão anaeróbia $\left(\mathrm{m}^{3}\right.$.dia-1); DQOe é o valor médio da demanda química de oxigênio da biomassa residual produzida ( $\mathrm{kg}$ DQO. $\mathrm{m}^{-3}$ de efluente); $Y$ é a produção de metano por $\mathrm{kg}$ de DQOe $\left(\mathrm{m}^{3} \mathrm{CH} 4 . \mathrm{kg}-1 \mathrm{DQOe}\right)$; e $C_{\mathrm{ch} 4}=$ é a concentração de metano no biogás (aproximadamente 60\% de metano).

\section{Estimativa de produção de eletricidade}

Para estimar a produção de energia e o potencial técnico de geração em estudo, utilizou a metodologia proposta pelo FINEP (2009), seguindo os seguintes parâmetros: Potencial teórico de produção de eletricidade (PTE), propondo-se a equação $P$ TE = P C I.PB, onde: $P T E$ = potencial teórico de produção de eletricidade $\left(\mathrm{kWh} \cdot \mathrm{dia}^{-1}\right) ; \mathrm{PCl}=$ poder calorífico inferior $\left(\mathrm{kWh} . \mathrm{m}^{-3}\right)$, considerou-se o valor de $6.5 \mathrm{kWh} \cdot \mathrm{m}^{-3}$ (aproximadamente $65 \%$ de metano); e $\mathrm{PB}=$ produção diária de metano $\left(\mathrm{m}^{3} \cdot \mathrm{dia}^{-1}\right)$; Potencial técnico de 
geração (PTCE), sugerindo-se PTCE=PTE.n/100, onde: PTCE = potencial técnico de produção de eletricidade $\left(\mathrm{kWh} \cdot \mathrm{dia}^{-1}\right)$; e $\eta$ = eficiência de conversão de, aproximadamente, $25 \%$.

\section{RESULTADOS}

\section{Estimativa de produção de biogás}

O presente trabalho apresenta como resultados a avaliação da estimativa de produção de biogás proveniente do tratamento do esgoto sanitário do Brasil e sua capacidade de geração de energia renovável para o ano de 2016. Os efluentes domésticos urbanos disponíveis em estações de tratamento de esgoto possibilitam a produção de biogás para geração de eletricidade, que é possível a partir da remoção da carga orgânica.

Tabela 3: Estimativa da produção de metano.

\begin{tabular}{|c|c|c|c|c|c|}
\hline & & Esgoto coletado e tratado & & & \\
\hline Região & Vazão média m/3 dia (Q) & $\mathrm{DQO} \mathrm{mg} / \mathrm{L}$ & $\mathrm{Y}(\mathrm{m} 3 / \mathrm{kg})$ & \% de $\mathrm{CH} 4$ & Produção de metano $\mathrm{Mm}^{3} /$ dia \\
\hline Nacional & 11.111 .900 & 350 & 0,2 & $60 \%$ & 466,70 \\
\hline Norte & 197.744 & 350 & 0,2 & $60 \%$ & 8,31 \\
\hline Nordeste & 1.571 .550 & 350 & 0,2 & $60 \%$ & 66,01 \\
\hline Sudeste & 6.799 .470 & 350 & 0,2 & $60 \%$ & 285,58 \\
\hline Sul & 1.547 .850 & 350 & 0,2 & $60 \%$ & 65,01 \\
\hline Centro-Oeste & 995.289 & 350 & 0,2 & $60 \%$ & 41,80 \\
\hline & & Esgoto coletado e não tratado & & & \\
\hline Região & Vazão média m/3 dia (Q) & $\mathrm{DQO} \mathrm{mg} / \mathrm{L}$ & $\mathrm{Y}(\mathrm{m} 3 / \mathrm{kg})$ & $\%$ de $\mathrm{CH} 4$ & PRODUÇÃO DE METANO Mm³/dia \\
\hline Nacional & $3.885 .072,00$ & 350 & 0,2 & $60 \%$ & 163,17 \\
\hline Norte & $49.796,71$ & 350 & 0,2 & $60 \%$ & 2,09 \\
\hline Nordeste & $371.126,90$ & 350 & 0,2 & $60 \%$ & 15,59 \\
\hline Sudeste & $3.272 .936,00$ & 350 & 0,2 & $60 \%$ & 137,46 \\
\hline Sul & $105.596,30$ & 350 & 0,2 & $60 \%$ & 4,44 \\
\hline Centro-Oeste & $85.612,75$ & 350 & 0,2 & $60 \%$ & 3,60 \\
\hline
\end{tabular}

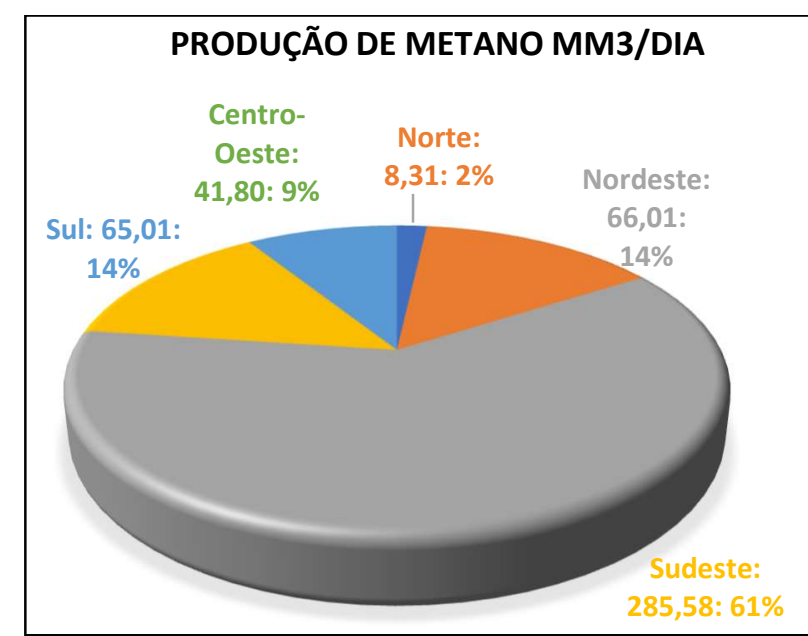

Figura 1: Estimativa da produção de metano do esgoto coletado e tratado.

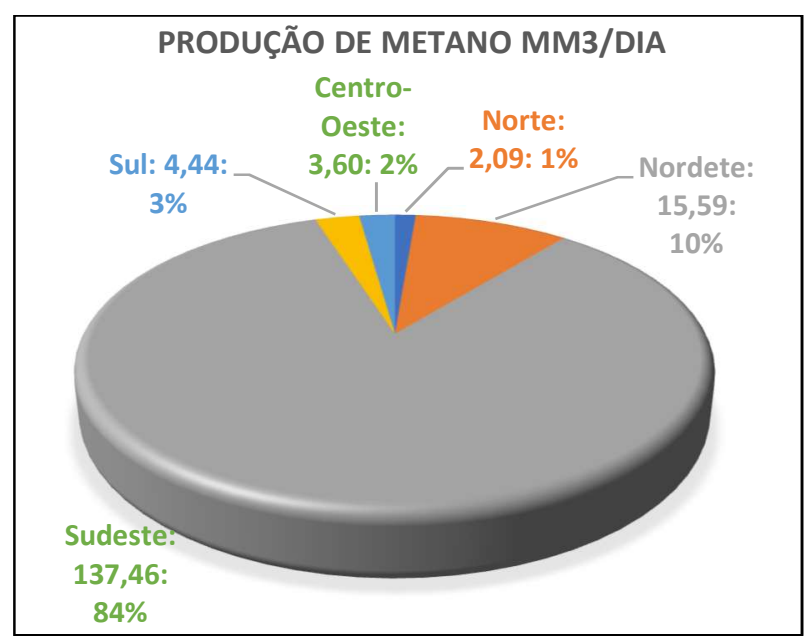

Figura 2: Estimativa da produção de metano do esgoto coletado e não tratado.

Conhecendo-se a vazão média de entrada do efluente no sistema de tratamento de esgoto, a demanda química de oxigênio (DQO) média num período e o índice de produção de biogás em função da DQO gerada, é possível fazer a estimativa como apresentado na metodologia. Foram realizados cálculos para o esgoto coletado e tratado, e para o esgoto coletado e não tratado no Brasil no ano de 2016 segundo SNIS. A tabela 3 e as figuras 1 e 2 apresentam a estimativa de produção de metano no âmbito nacional e nas regiões 
do Brasil. Para calcular a produção estimada do biogás foram usados os seguintes indicadores técnicos: DQO removida, $(350 \mathrm{mg} / \mathrm{L})$ de acordo com a literatura analisada; Média de vazão $\left(\mathrm{m}^{3} /\right.$ dia); Produção de metano por Kg de DQO removida (Y); e Concentração de metano (60\%).

\section{Estimativa de produção de energia elétrica}

Para a estimativa da geração de energia e seu potencial técnico de geração, foi utilizada a metodologia proposta pelo FINEP (2009), no qual foi considerado o potencial teórico de produção de eletricidade (kWh.dia-1), o poder calorifico inferior PCl (kWh.m-3), que no presente estudo foi adotado um valor de 6.5, que equivale a aproximadamente $65 \%$ de metano, valor que, de acordo com a literatura, é a porcentagem estimada da qualidade do metano no processo de biodigestão anaeróbica do esgoto, e a eficiência da conversão do metano, que é em torno de $25 \%$ e a produção estimada diária do biogás (m3.dia1). 0 resumo e a produção de energia estão apresentados na tabela 4 e nas figuras 3 e 4 .

Tabela 4: Estimativa do potencial técnico da produção de energia elétrica.

\begin{tabular}{|c|c|c|c|}
\hline & Esgoto coletado e tratado & & \\
\hline Região & PRODUÇÃO DE METANO Mm³/dia & PTE (GWh.dia-1) & $\begin{array}{c}\text { PTCE } \\
\text { (GWh.dia-1) }\end{array}$ \\
\hline Nacional & 466,70 & 3.034 & 7,583 \\
\hline Norte & 8,31 & 54 & 0,134 \\
\hline Nordeste & 66,01 & 429 & 1,072 \\
\hline Sudeste & 285,58 & 1.856 & 4,640 \\
\hline Sul & 65,01 & 423 & 1,056 \\
\hline \multirow[t]{2}{*}{ Centro-Oeste } & 41,80 & 272 & 0,679 \\
\hline & Esgoto coletado e não tratado & & \\
\hline Região & PRODUÇÃO DE METANO Mm³/dia & PTE (GWh.dia-1) & $\begin{array}{c}\text { PTCE } \\
\text { (GWh.dia-1) }\end{array}$ \\
\hline Nacional & 163,17 & 1060,624 & 2,651 \\
\hline Norte & 2,09 & 13,594 & 0,033 \\
\hline Nordeste & 15,59 & 101,317 & 0,253 \\
\hline Sudeste & 137,46 & 893,511 & 2,233 \\
\hline Sul & 4,44 & 28,827 & 0,072 \\
\hline Centro-Oeste & 3,60 & 23,372 & 0,058 \\
\hline
\end{tabular}

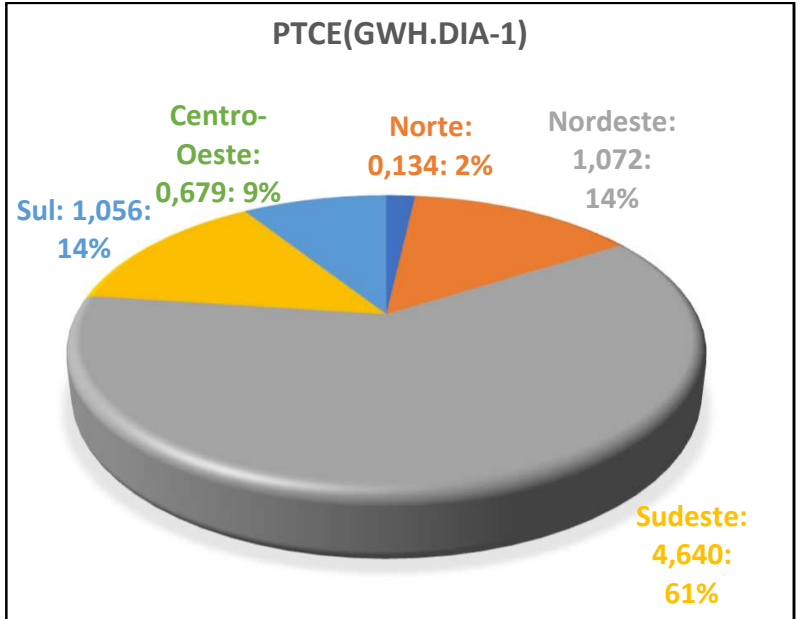

Figura 3: Estimativa do potencial técnico da produção de energia elétrica do esgoto coletado e tratado.

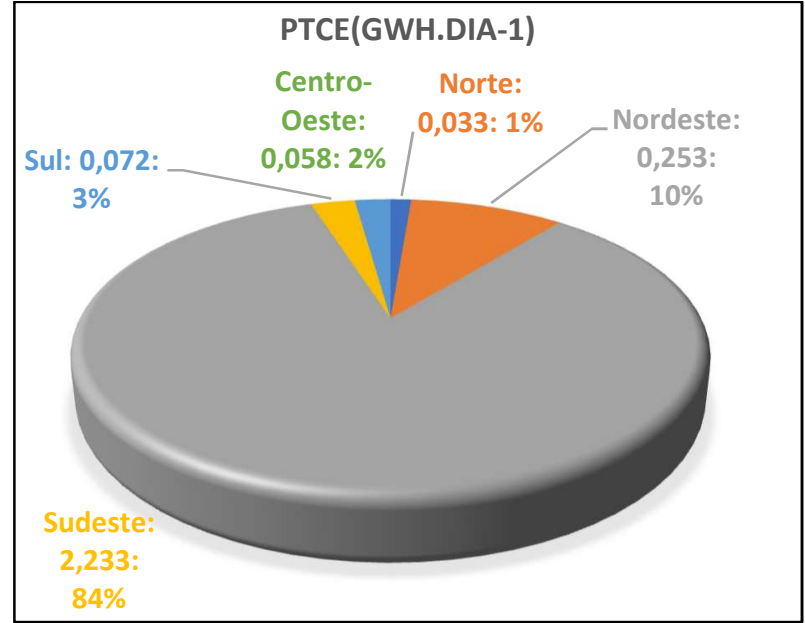

Figura 4: Estimativa do potencial técnico da produção de energia elétrica do esgoto coletado e não tratado.

\section{DISCUSSÃO}

A capacidade de produção do biogás no âmbito Nacional apresentou a quantia de 466,7Mm3/dia e $163,17 \mathrm{Mm} 3 /$ dia para o esgoto coletado e tratado, e para o esgoto coletado e não tratado, respectivamente. 
Das regiões do Brasil a que apresentou uma maior capacidade no potencial técnico de geração de energia elétrica, foi a região Sudeste, com a quantia de 4,640GWh.dia-1 e 2,23GWh.dia-1 para o esgoto coletado e tratado, e para o esgoto coletado e não tratado, respectivamente. Isso se dá por apresentar uma vazão média de esgoto maior e consequentemente uma maior capacidade de geração do biogás.

O potencial técnico de geração de eletricidade no âmbito Nacional para o esgoto coletado e tratado, e o esgoto coletado e não tratado foram de 7,583GWh.dia-1 e 2,651 GWh.dia-1, respectivamente. Os resultados obtidos com o potencial técnico de geração do esgoto coletado e tratado equivalem anualmente a cerca de $0,48 \%$ de toda a produção elétrica no Brasil. Essa porcentagem pode chegar $0,64 \%$ se caso todo o esgoto coletado no brasil fosse tratado e submetido ao aproveitamento energético.

Não a outras referências bibliográficas de outros autores a respeito da capacidade de produção de energia elétrica utilizando o biogás proveniente da degradação da matéria orgânica do esgoto doméstico urbano, no âmbito Nacional e das regiões do Brasil, nesse intuito foi realizado o estudo para estimar a capacidade de geração de biogás proveniente dos efluentes domésticos urbanos do brasil e de suas regiões e seu uso como fonte alternativa na geração de energia elétrica.

\section{CONCLUSÃO}

Contudo, como visto anteriormente, a utilização do biogás traz benefícios tanto para o meio ambiente, quanto no gerenciamento dos resíduos no país, geração de eletricidade, possibilidade de geração de emprego, etc.. Parte da demanda de energia elétrica do Brasil poderia ser suprido pela utilização do biogás. Para o presente estudo podem-se estabelecer as seguintes conclusões: o potencial de geração do metano no âmbito Nacional para o esgoto coletado e tratado, e o esgoto coletado e não tratado, foram de $466,70 \mathrm{Mm}^{3} /$ dia e de $163,17 \mathrm{Mm}^{3} /$ dia, respectivamente; e devido ao potencial ser reduzido em relação à outras fontes de energia como a solar por exemplo, entende-se como ganho nessa utilização apenas o uso local, em sistema de cogeração para redução de despesas operacionais. O pequeno potencial, associado à característica de distribuição geográfica, ratifica essa asserção de uso em modelo de geração distribuída.

\section{REFERÊNCIAS}

BURTON, F. L.; STENSEL, H. D.. Wastewater engineering: treatment and reuse. 4 ed. New York: Mc Graw Hill, 2005.

CASTANÓN, N. J. B.. Biogás, originado a partir dos rejeitos rurais, Trabalho apresentado na disciplina: Biomassa como Fonte de Energia: Conversão e utilização. São Paulo: USP, 2002.

FARIA, R. A. P.. Avaliação do potencial de geração de biogás e de produção de energia a partir da remoção da carga orgânica de uma estação de tratamento de esgoto-estudo de caso. Dissertação (Mestrado em Energia na Agricultura) Universidade Estadual do Oeste do Paraná, Cascavel, 2012.

FINEP. Financiadora de Estudos e Projetos. Projeto Geração Distribuída: Relatório Técnico Parcial: Revisão Bibliográfica: Geração Distribuída de Energia Elétrica a Biogás com Saneamento Ambiental. Foz do Iguaçu: FINEP, 2009.
GenOVESE, A. L.; UDAETA, M. M.; GALVAO, L. C. R.. Aspectos energéticos da biomassa como recurso no Brasil e no mundo. In: ENCONTRO DE ENERGIA NO MEIO RURAL. Anais. Campinas: 2006.

GONÇALVES, F. B.; SOUZA, A. P.. Disposição oceânica de esgotos sanitários: história e prática. Rio de Janeiro: ABES, 1997.

IANNICELLI, L. A.. Reaproveitamento energético do biogás de uma indústria cervejeira. Dissertação (Mestrado em Engenharia Mecânica) - Universidade de Taubaté, Taubaté, 2008.

SALOMON, K. R.. Avaliação Técnico-Econômica e Ambiental da Utilização do Biogás Proveniente da Biodigestão da Vinhaça em Tecnologias para Geração de Eletricidade. Tese 
(Doutorado em Engenharia Mecânica) - Universidade Federal de Itajubá, Itajubá, 2007.

SOUSA, J. T.; HAANDEL, A.; LIMA, E. P. C.. Use of constructed wetland for the post-treatment of domestic sewage anaerobic effluent from UASB reactor. Engenharia Sanitária e Ambiental, v.9, n.4, p.285-290, 2004.

SOUZA, R. G.; SILVA, F. M.; BASTOS, A. C.. Desempenho de um conjunto motogerador adaptado a biogás. Ciência e Agrotecnologia, Lavras, v.34, n.1, p.190-195, 2010.

A CBPC - Companhia Brasileira de Produção Científica (CNPJ: 11.221.422/0001-03) detém os direitos materiais desta publicação. Os direitos referem-se à publicação do trabalho em qualquer parte do mundo, incluindo os direitos às renovações, expansões e disseminações da contribuição, bem como outros direitos subsidiários. Todos os trabalhos publicados eletronicamente poderão posteriormente ser publicados em coletâneas impressas sob coordenação da Sustenere Publishing, da Companhia Brasileira de Produção Científica e seus parceiros autorizados. Os (as) autores (as) preservam os direitos autorais, mas não têm permissão para a publicação da contribuição em outro meio, impresso ou digital, em português ou em tradução. 